\title{
The molecules we eat: Food as a medium to communicate science
}

Amy C Rowat

\begin{abstract}
Creative, inquiry-driven approaches in science education help to address the growing need to effectively engage students and promote the public understanding of science. Here we describe an interactive format using food that can be applied both in a course for undergraduate students, as well as in a lecture for the general public. Communicating science through food may also dispel fear of naturally occurring chemicals as well as scientific misconceptions that are propagated by the media.
\end{abstract}

Keywords: Science education, General education, Public understanding of science

\section{Introduction}

Each day we consume a very large quantity of molecules. For example, a glass of water and a serving of steak each contain over $10^{24}$ molecules. These molecules are major determinants of food texture and flavor; they are also essential for an array of physiological functions in plants and animals that we eat. In particular, proteins, carbohydrates, and lipids are major determinants of the physical and mechanical properties of cells and nuclei. For example, the gluten protein network imparts a remarkable stretchiness to strudel dough; the carbohydrates that constitute plant cell walls are important for vegetable texture. Understanding the physical and molecular origins of the texture of cells, tissues, and biological materials is a major focus of research in our laboratory. Naturally, the major themes of our research share many commonalities with food; our findings may thus also provide unique perspective into the foods that we eat.

Using food as a medium for teaching, we have been developing methods to captivate people in science. Engaging students in science education through food and cooking has been successful in many contexts around the world [1-6]. Food can incite curiosity about everyday foods that we eat and is also an excellent, inexpensive tool for experimentation. Here we highlight some central concepts of our interactive approach to communicating science for a general audience. ${ }^{\mathrm{a}}$

Correspondence: rowat@ucla.edu

Department of Integrative Biology \& Physiology, University of California, Los Angeles, CA 90095, USA
Science in the molecules we eat

Taste tests for teaching quantitative science and scientific inquiry

Scientific lectures are an important component of teaching science. We also provide interactive demonstrations and activities to more fully engage participants in scientific concepts. For example, taste tests are an enticing way to further draw people in to learning scientific concepts. To demonstrate phase transitions and the effect of molecular composition on phase behavior, a popular taste test involves comparing milk and dark chocolates. Such a gustatory method also requires that individual audience members become scientists as they make observations of chocolate texture and flavor, while learning of the underlying scientific basis of these physical properties [7]. In a lecture on diffusion, taste tests of tofu marinated in soya sauce for 2 versus 24 hour intervals provide unforgettable experiences of the time and length scales of diffusion.

To ground the sensory observations of the taste experiments in the framework of quantitative science, simple analyses can yield interesting insights into the physical basis of phenomena in food and cooking. For example, diffusion underlies a multitude of processes in food and cooking ranging from irrigation to heat transfer to flavor infusion by marinating. The time and length scales of diffusion can be quantitatively understood in terms of the diffusion coefficient, as well as Fick's First Law: the flux of molecules (mass transport) is proportional to the concentration gradient, as described by $J_{x}--D \frac{d c}{d x}$, where $J_{\mathrm{x}}$ is the solute flux, $D$ is the diffusion coefficient, $d c$ denotes 
the solute concentration difference, and $d x$ is the relevant length scale. To illustrate the beauty and utility of Fick's First Law, we recently developed a simple hands-on experiment that requires students to perform an experiment, collect and analyze data, and interpret the results: by determining the mass of mushrooms over time during osmotic shrinkage (salting), together with simple geometric considerations and calculations, one can determine the diffusion coefficient of water, which turns out to be approximately $10^{-5} \mathrm{~m}^{2} / \mathrm{s}$; this value is about $10,000 \times$ greater than the expected diffusion coefficient of water. Yet one can make sense of these results by careful observations and logical reasoning: mushrooms typically float in water, as they largely consist of air; the diffusion coefficient of water in air is approximately $10,000 \times$ faster than in water. An added bonus of food experiments is that students can eat their lab exercises: after calculating the diffusion coefficient, the saltpickled mushrooms can be used in 'Marinated tofu wraps with salt-pickled mushrooms' (L. Zhou and A.C. Rowat, unpublished). Indeed, recipes provided throughout the class ranging from horchata to slow-roasted pork shoulder are popular among the students, and incite greater awareness of preparing and eating good food.

\section{Guest lecturers provide complementary perspective on the molecules we eat}

To bring culinary perspective to complement the scientific perspective of food, we incorporate chefs, farmers, and other food artisans into the classroom; this challenges students to integrate their newfound knowledge of science with cuisine and gastronomy. For example, noma chefs René Redzepi and Lars Williams are renowned for foraging the Danish wilds to discover novel foods and flavors. For a recent lecture in an undergraduate class at University of
California, Los Angeles, they discussed their recent foray into the world of insects. Using insects, the duo is generating innovative flavors, however, eating these critters can challenge the common Western aversion to eating bugs. Yet inspecting the molecular composition of crickets reveals they have similar molecular composition to many foods that we eat $[8,9]$. Moreover, performing a simple calculation based on the average energetic content of carbohydrates, proteins, and fats, 4,4 , and $9 \mathrm{Cal} / \mathrm{g}$, respectively, reveals that crickets have a relatively high protein and low fat content: a 100 g serving contains 5.1 g carbohydrates, $12.9 \mathrm{~g}$ protein, and $5.5 \mathrm{~g}$ fat $[8,9]$. Eating a single serving of crickets is thus nutritionally beneficial: it contains only 122 Calories, with $26 \%$ of the recommended daily intake of proteins. ${ }^{\text {b }}$

Farmers also provide unique insight that complements the scientific perspective of food. A major focus of some Californian farmers including Barbara Spencer, Windrose Farms, and Cynthia Sandberg, Love Apple Farms, is the importance of temperature for the flavor of fruits and vegetables. Understanding how temperature impacts the sugar content of winter vegetables, such as the sweetness of winter carrots, frames the concept of freezing point depression in a novel way that captivates student interest. For instance, the sweetness of winter carrots is a fine example of freezing point depression. There are many other excellent physiological examples of altered molecular compositions in organisms for temperature and pressure adaptation, such as freezing resistance in some Antarctic fishes [10]. From a scientific perspective, freezing point depression and boiling point elevation can be quantitatively described by $\Delta T_{\mathrm{b}}$ or $\mathrm{f}=b \cdot K_{\mathrm{b}}$ or $\mathrm{f}$. where $\Delta T$ is the magnitude of change in temperature, $b$ is the molality of the solute, and $K_{\mathrm{b}}$ or $\mathrm{f}$ is a constant; for water,

a

INGREDIENTS: CACAO BEANS; SUGAR; COCOA BUTTER; NON-GMO SOY LECITHIN; AND WHOLE VANILLA BEANS.

b

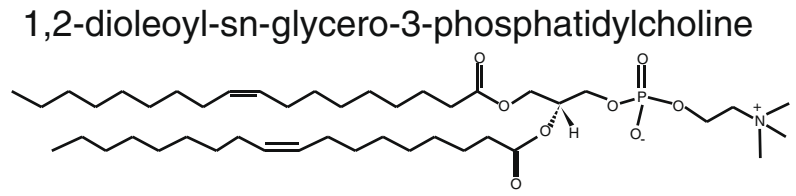

1-palmitoyl-2-oleoylphosphatidylcholine

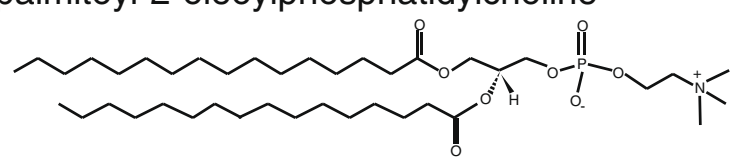

C

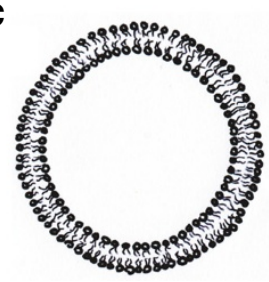

Figure 1 The molecules we eat. (a) Lecithin is essential in common foods, such as chocolate. (b) Lecithin consists of lipid molecules, such 1-palmitoyl-2-oleoylphosphatidylcholine and 1,2-dioleoyl-sn-glycero-3-phosphatidylcholine. (c) Lipid molecules spontaneously assemble into lipid bilayers, as shown in this schematic illustration. Lipid bilayers are the foundation of biological membranes that delineate cells and intracellular organelles. 
$K_{\mathrm{f}}=1.86 \mathrm{~K} \mathrm{~kg} / \mathrm{mol}$. This simple equation can be applied to calculate the effects of physiological concentrations of solute on freezing points. Informal student feedback suggests that learning of the origins of the molecules that we eat can also bring new appreciation and awareness of food; this is particularly important in an era where knowledge of the origins of basic foods is lacking [11-13].

\section{Molecules in the media: communicating science to a general audience}

Many of the concepts in the program Science \& Food provide powerful material to enthrall a general audience in deepening their knowledge of science. Promoting the public understanding of science is essential, especially in light of misinformation that can be propagated through the media and generates fear of molecules. For example, in a recent book by Michael Pollan, he describes Rules to Eat [14]: 'Avoid food products containing ingredients that a thirdgrader cannot pronounce.' 'Avoid food products that contain more than five ingredients.' 'Avoid food products containing ingredients that no ordinary human would keep in the pantry. ...Cellulose? Xanthan gum?... Whether or not any of these additives pose a proven hazard to your health, many of them haven't been eaten by humans for very long, so they are best avoided.' Such misinformation highlights the need to promote scientific literacy: cellulose is an essential molecule of plants. Many multisyllabic molecules may indeed pose a challenge for a third grader to pronounce, such as 1-palmitoyl-2-oleoylphosphatidylcholine and 1,2-dioleoyl-sn-glycero-3-phosphatidylcholine (Figure 1). Yet these lipid molecules are essential components of the lipid membranes that provide an essential barrier for individual cells. Phospholipids naturally occur in many other foods such as cacao beans [15], as well as egg yolk. Lecithin is also an effective emulsifier that is commonly added to chocolate (Figure 1), as well as other foods. Starting with the simple task of deciphering ingredient labels $[7,16]$, scientists can play an important role in promoting scientific literacy and dispelling fear of molecules.

\section{Research inspired by the kitchen}

An unexpected outcome of communicating science using food is that methods from the kitchen can impact research in our laboratory. In a recent undergraduate student project, students studied the mechanism of nitrous oxide to extract flavor from herbs. While nitrous oxide pressurization is commonly used for generating foams such as whipped cream, this method is also used to extract flavors from herbs $[17,18]$. The proposed mechanism for flavor extraction is mechanical disruption of cells upon pressure release, whereby the bubbles of nitrous oxide gas increase in size, and thereby disrupt cellular structures, such as lipid membranes [19]. Our preliminary results show that this method can also be used for subcellular fractionation and nuclear isolation protocols, where rupturing the plant cell wall is a prerequisite to liberating the internal contents of the cell. Using nitrous oxide pressurization can potentially provide a faster and easier way to disrupt plant cells: in contrast to other protocols, this method could sidestep the need for enzymatic treatment, which can be costly and time-consuming.

\section{Summary}

Based on preliminary student and audience feedback, communicating science using the tactile medium of food is an effective method to engage people in scientific inquiry. Food can also captivate people to understand more about the molecular and scientific basis of the foods, cells and nuclei that we eat. Given the increasing demand to promote knowledge of science and the origins of the foods that we eat, such dialogue on science and food is essential.

\section{Endnotes}

${ }^{a}$ More detailed information of topics and exercises is presented at scienceandfood.org.

${ }^{\mathrm{b}}$ Percent daily values based on a 2,000 Calorie diet.

\section{Competing interests}

The author declares that she has no competing interests.

\section{Acknowledgements}

The author acknowledges the Gastrophysical Society and the Office of Instructional Development at UCLA for supporting Science \& Food course development.

Received: 8 November 2012 Accepted: 8 November 2012

Published: 9 January 2013

\section{References}

1. Barham P: The science of cooking. Berlin: Springer-Verlag; 2001

2. Jacobs H: The molecular biology of the hamburger. EMBO Rep 2011, 12:609.

3. Simek JW, Pruitt BA: Food chemistry for non-science majors. J Chemical Education 1979, 56:230

4. Wolf LK: Kitchen chemistry classes take Off. Chem Eng News 2012, 90:74-75.

5. Miles DT, Bachman JK: Science of food and cooking: a Non-science majors course. J Chem Education 2009, 86:311-315.

6. Grosser AE: Cooking with chemistry. J Chemical Education 1984, 61:362-363.

7. Rowat AC, Rosenberg D, Hollar KA, Stone HA: The science of chocolate: interactive activities on phase transitions, emulsification, and nucleation. J Chemical Education 2010, 88:29-33.

8. lowa State Entymology Department: Insect Nutritional Table. http://www.ent.iastate.edu/misc/insectnutrition.html.

9. Berenbaum MR: Bugs in the system: insects and their impact on human affairs. Jackson, TN: Perseus Books; 1995.

10. de Vries AL, Wohlschlag DE: Freezing resistance in some Antarctic fishes. Science 1969, 163:1073-1075.

11. Jamie Oliver's food revolution (VIDEO): first graders can't identify fruits, veggies. In Huffington Post. Edited by. 2010. http://www.huffingtonpost. com/2010/02/26/jamie-olivers-food-revolu_n_478824.html.

12. Where do milk, eggs and bacon come from? One in three youths don't know. In The Telegraph. London: Food and Drink News; 2012. http://www. 
telegraph.co.uk/foodanddrink/foodanddrinknews/9330894/Where-do-milkeggs-and-bacon-come-from-One-in-three-youths-dont-know.html.

13. Spiegel JE: Introducing children to the sources of food. In The New York Times. Edited by. New York: NY Region; 2012.

14. Pollan M: Food rules: an eater's manual. New York: Penguin Books; 2009.

15. Bertazzo A, Comai S, Mangiarini F, Chen S: Composition of cacao beans. Chocolate in Health and Nutrition 2013, 7:105-117.

16. Rowat AC, Rosenberg D, Hollar KA, Stone HA: The science of pizza: the molecular origins of cheese, bread, and digestion using interactive activities for the general public. J Food Sci Education 2010, 9:106-112.

17. Lersch M: Wonders of extraction: pressure. http://blog.khymos.org/2010/08/ 21/wonders-of-extraction-pressure.

18. Arnold D: Infusion profusion: game-changing fast ' $\mathrm{N}$ cheap technique. In Cooking Issues. Edited by. Cooking Issues. http//www.cookingissues.com/2010/ 08/11/infusion-profusion-game-changing-fast-\%E2\%80\%98n-cheap-technique.

19. Chin JH, Trudell JR, Cohen EM: The compression-ordering and solubilitydisordering effects of high pressure gases on phospholipid bilayers. Life Sci 1976, 18:489-498.

doi:10.1186/2044-7248-2-10

Cite this article as: Rowat: The molecules we eat: Food as a medium to communicate science. Flavour 2012 2:10.

\section{Submit your next manuscript to BioMed Central and take full advantage of:}

- Convenient online submission

- Thorough peer review

- No space constraints or color figure charges

- Immediate publication on acceptance

- Inclusion in PubMed, CAS, Scopus and Google Scholar

- Research which is freely available for redistribution 